\title{
ĐÁNH GIÁ RỦI RO SỬC KHỎE ĐỐI VỚI SỰ HIẸN DIỆN CỦA MộT SỐ NGUYÊN TỐ PHÓNG XẠ (U VÀ Th) TRONG NƯỚC DƯỚI ĐẤT KHU VỰC NGOẠI THÀNH TP. HCM
}

\author{
Hoàng Thị Thanh Thủy ${ }^{1}$ Từ Thị Cẩm Loan¹, Cấn Thu Văn1, Văn Tuấn Vũ ${ }^{1}$
}

Tóm tắt: Bài báo trình bày các kết quả nghiên cưu rủi ro súc khỏe do sụ hiện diện của hai nguyên tố phóng xạ Urani (U) và Thori (Th) trong ba tầng chứa nước Pleistocen (Pleistocen duoói (qp I), Pleistocen giũua-trên (qp 2-3) và Pleistocen trên (qp 3$)$ ) ở khu vực ngoại thành TP.HCM. Kết quả phân tích cho thấy hàm luợng hai nguyên tố phóng xạ thể hiện giá trị nền và thấp hơn các khu vực trên thế giới. Kết quả tính toán chi số đánh giá rủi ro sức khỏe (HQ) của tất cả nguyên tố khảo sát thể hiện chưa có nguy co ảnh hưởng tiêu cưc đến sức khỏe $(H Q<1)$. Tuy nhiên, ở một số vị trí đã có sự tăng cao hàm lượng U trong tầng chưa nước pleistocen trên, có thể do ảnh hưởng hoạt động nhân sinh. Do đó, vẫn cần có các nghiên cưu chi tiết hơn để có kết luận chính xác về rủi ro của các nguyên tố khảo sát.

Từ khóa: Nước dưới đất, nguyên tố phóng xạ, urani, thori, đánh giá rủi ro, rủi ro sức khỏe.

Ban Biên tập nhận bài: 22/2/2020 Ngày phản biện xong: 18/3/2020 ～Ngày đăng bài: 25/3/2020

\section{Mở đầu}

Thành phố Hồ Chí Minh có trữ lượng nước dưới đất khá phong phú ước tính khoảng 2,5 triệu $\mathrm{m}^{3}[2]$. Hai tầng Pleistocen và Pliocen là hai tầng có trữ lượng khai thác nhiều nhất. Vì vậy, cần đánh giá chất lượng nước dưới đất để người dân có thể sử dụng một nguồn nước an toàn, nhất là đối với tầng nông (Pleistocen) có liên quan mật thiết đến các hoạt động nhân sinh. Trên địa bàn TP. HCM, bên cạnh nguồn nước cấp thì ở khu vực ngoại thành vẫn còn các khu vực sử dụng nước dưới đất trong sinh hoạt như các quận 12, huyện Bình Chánh, Hóc Môn và Củ Chi. Do đó, khu vực này đã được lựa chọn để khảo sát.

U và Th là hai họ phóng xạ cơ bản trên Trái đất $[5,8]$. Các nguyên tố phóng xạ $U$ và Th có thể hiện diện trong nước dưới đất do quá trình tự nhiên và nhân tạo. Nguồn cung cấp tự nhiên là quá trình phong hóa các khoáng vật có chứa nguyên tố phóng xạ, quá trình vận chuyển trong không khí và dòng chảy mặt. Th nằm trong các hợp chất khó hòa tan, hầu như không có mặt trong nước dưới đất cũng như nước bề mặt. Trong khi đó, U không bao giờ tồn tại độc lập trong tự nhiên mà thường tồn tại ở các dạng: hòa tan, hấp phụ, lơ lửng. Dạng tồn tại của $U$ phụ thuộc vào độ $\mathrm{pH}, \mathrm{Eh}$, chất keo, thành phần hữu cơ. Trong tự nhiên, U luôn kết hợp với oxy để tạo nên oxit trong hyđroxit. Trong môi trường axit (độ $\mathrm{pH}$ thấp: $\leq 4$ ) và môi trường kiềm (độ $\mathrm{pH}$ cao: $\geq 8$ ), U dễ bị hòa tan và vận chuyển dưới dạng các hợp chất. Nồng độ U trong nước có mối tương quan với hàm lượng của một số ion và một số nguyên tố khác $\left(\mathrm{CO}_{3}{ }^{2}, \mathrm{PO}_{4}^{3-}, \mathrm{Na}^{+}, \mathrm{K}^{+}, \mathrm{Mg}^{2+}\right.$, $\mathrm{Fe}^{2+}$ ). Trong môi trường địa hóa thuận lợi, các hợp chất của $U$ dễ dàng bị hòa tan và di chuyển trong nước [5]. Nhìn chung trong điều kiện tự nhiên cả hai $U$ và $T h$ thường hiện diện trong nước dưới đất ở hàm lượng thấp. Một số nghiên cứu ở nước ngoài cũng đã xác nhận một số dị thường $\mathrm{U}$ và $\mathrm{Th}$ liên quan đến đặc điểm địa chất. Murad và ctv. 2014 khi nghiên cứu thành phần hóa học nước dưới đất ở các tiểu vương quốc Ả rập thống nhất (UAE) đã cho thấy hàm lượng $\mathrm{U}$ và Th tuy thể hiện khoảng biến thiên khá lớn với một số dị thường nhưng nhìn chung vẫn ở mức thấp, nằm trong giới hạn cho phép của Tổ chức y tế thế giới (WHO) [6]. Cụ thể, khoảng biến 
thiên của hai nguyên tố phóng xạ này như sau $\mathrm{U}$ $(0,125-508) \mathrm{ng} / \mathrm{l}$ và $\mathrm{Th}(0,236-2.529) \mathrm{ng} / \mathrm{l}$. Các vị trí có hàm lượng cao có tương quan chặt chẽ với hàm lượng tổng chất rắn hòa tan và ở khu vực phân lớp đá vôi và đá phiến. Tương tự, Lauria và ctv, 2004 cũng cho thấy sự biến thiên khá lớn hàm lượng $\mathrm{U}$ và $\mathrm{Th}$ trong nước dưới đất ở khu vực đầm Buena (Bang Rio de Janeiro, Brazil). Hàm lượng $U$ thay đổi trong khoảng $\mathrm{KPH}-3.720 \mathrm{ng} / \mathrm{l}$ và Th từ KHP-250 ng/L [4]. Tuy nhiên, theo Babu 2008, ở một số vị trí thuộc tỉnh Kolar (Ấn độ) đã xuất hiện các dị thường $U$ cao hơn giới hạn cho phép của WHO và có thể gây rủi ro đến sức khỏe cộng đồng. Hàm lượng $\mathrm{U}$ biến thiên từ 300 đến $1442 \times 10^{3} \mathrm{ng} / \mathrm{l}$. Các dị thường này có liên hệ với các thành tạo granit ở khu vực nghiên cứu [1]. Sự gia tăng hàm lượng U trong nước dưới đất ở mỏ quặng đất hiếm cũng đã được đề cập đến trong nghiên cứu ở Việt Nam [10]. Bên cạnh nguồn tự nhiên, các nguồn nhân tạo của hai nguyên tố phóng xạ bao gồm quá trình khai thác các mỏ phóng xạ, nhà máy điện hạt nhân, đốt nhiên liệu hóa thạch và sử dụng phân bón phosphate trong nông nghiệp [11].

Hiện tại, Cơ quan Bảo vệ Môi trường Hoa Kỳ (EPA) đã phân loại U là chất gây ung thư ở người (nhóm $\mathrm{A}$ ) và quy định giới hạn an toàn là không (0) trong nguồn nước. Mặc dù, dựa trên các tài liệu địa chất thì tầng chứa nước Pleistocene khu vực TP.HCM đặc trưng là trầm tích nguồn gốc sông, sông - biển, Kết quả phân tích thành phần khoáng vật đã cho thấy chủ yếu là thạch anh, felspat, các sulfua của Fe chưa thấy sự hiện diện của các khoáng vật có thể chứa $\mathrm{U}$ và Th [8]. Nhưng bên cạnh đó, các hoạt động công nghiệp, nông nghiệp và đô thị ở TP.HCM vẫn có thể là nguồn ô nhiểm tiềm ẩn. Về mặt khoa học, ở khu vực TP.HCM các nghiên cứu về $U$ và sản phẩm phân rã Th trong nước dưới đất còn rất hạn chế và đặc biệt chưa có nghiên cứu về đánh giá rủi ro đối với các nguyên tố này. Chính vì vậy, rất cần triển khai các nghiên cứu về sự hiện diện và rủi ro của $U$ và $T h$ trong tầng cấp nước để đảm bảo an toàn cho sức khỏe cộng đồng. Bài báo trình bày các kết quả nghiên cứu bước đầu về hàm lượng các nguyên tố $U$ và $T h$ trong nước dưới đất và đánh giá rủi ro đến sức khỏe ở khu vực ngoại thành TP. HCM.

\section{Phương pháp nghiên cứu}

\subsection{Phương pháp lấy mẫu và phân tích mẫu}

Mười một mẫu nước dưới đất đã được thu thập cùng với đợt quan trắc quốc gia của Liên đoàn Điều tra và Quy hoạch tài nguyên nước miền Nam vào tháng 10 năm 2017. Các vị trí lấy mẫu là các giếng quan trắc quốc gia được thể hiện tại Hình 1. Phần mô tả các vị trí lấy mẫu được trình bày tại phụ lục 1 . Thiết bị lấy mẫu là bơm chìm đường kính $73 \mathrm{~mm}$. Nước sau khi được bơm được xả trong vòng 15 phút để cặn bẩn trôi hết. Trước khi cho mẫu vào bình nhựa, súc rửa chai 3 lần bằng nước của khu vực lấy mẫu. Lấy mẫu vào bình (không lấy đầy bình), đậy nắp, Sau đó cố định mẫu tại hiện trường bằng $1 \mathrm{ml}$ axit nitric đậm đặc $65-68 \%$ cho 1 lít mẫu để $\mathrm{pH}<2$, bọc mẫu bằng bọc nylon bỏ vào thùng đá và được vận chuyển về phòng thí nghiệm.

Mẫu sau khi chuyển về phòng thí nghiệm được bảo quản trong tủ mát ở $2-8^{\circ} \mathrm{C}$, được đo trong vòng một tuần. Mẫu được lọc qua màng lọc PTFE với đường kính lỗ lọc $0,45 \mu \mathrm{m}$ trước khi được phân tích bằng thiết bị ICP-MS (Inductively Coupled Plasma Mass Spectrometry) theo EPA (2008) "Dertermination of trace elements in water and wastes by inductively coupled plasma - mass spectrometry”. Các mass định lượng là 232 (Th) và 235 (U). Mỗi mẫu được đo lặp lại 3 lần với các thông số chạy máy như sau:

- Tốc độ bơm: 40 vòng/phút;

- Vận tốc khí Cool gas: 14 L/phút;

- Auxiliary gas: 0,8 L/phút;

- Nebulizer gas: 0,97 L/phút;

- Tổng thời gian phân tích 1 mẫu: $120 \mathrm{~s}$.

Dãy chuẩn làm việc gồm 10 điểm chuẩn. Cứ trung bình sau khi đo 10 mẫu tiến hành đo mẫu chuẩn để xác định độ ổn định của thiết bị. 


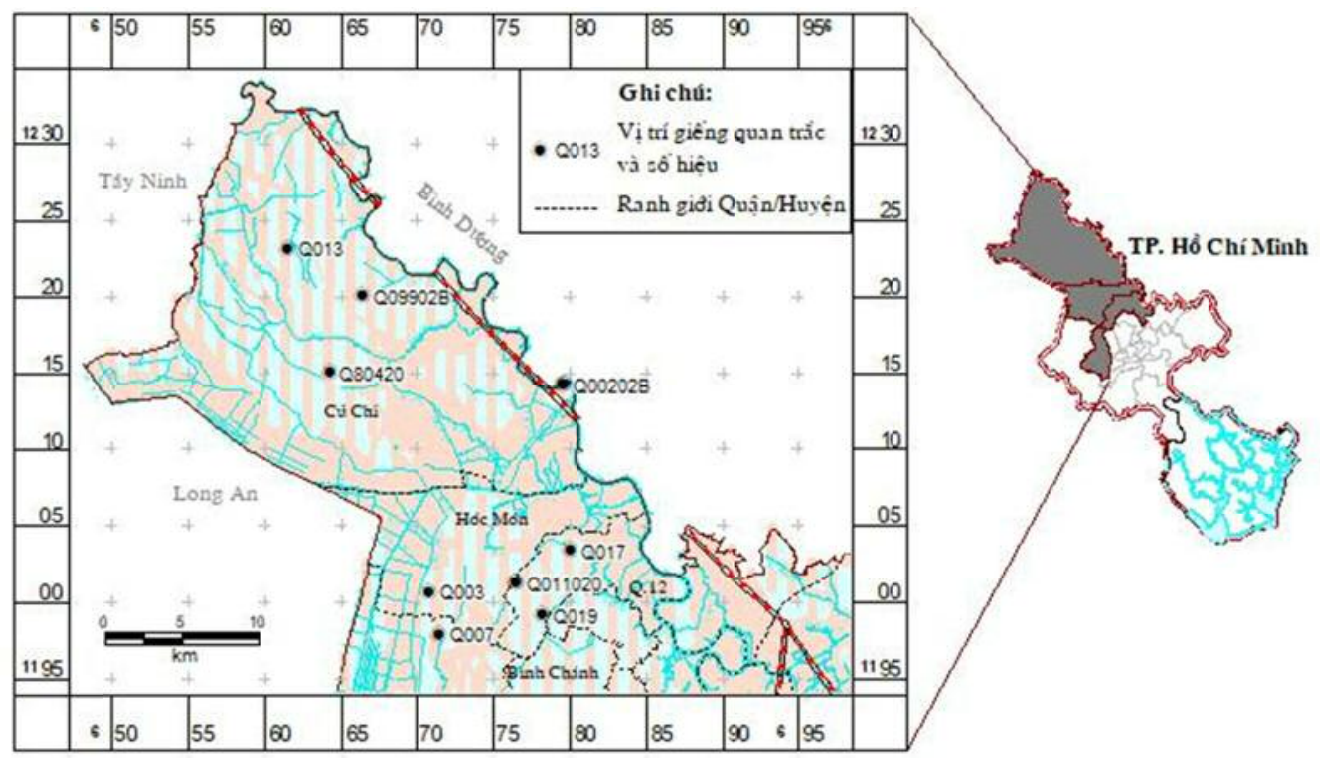

Hình 1. So đồ vị trí các giếng quan trắc

\section{2. Đánh giá rủi ro}

Đánh giá rủi ro là các quá trình ước tính xác suất xảy ra sự việc và mức độ của các tác động sức khỏe bất lợi trong một khoảng thời gian xác định. Theo Cơ quan Bảo vệ môi trường Hoa Kỳ USEPA (1992) phương pháp đánh giá rủi ro đối với chất ô nhiễm trong nước dưới đất như sau [7, 12]:

- Đánh giá liều trung bình hằng ngày ( $\mathrm{ADD})$ được tính toán dựa trên cường độ, tần suất và thời gian tiếp xúc của con người đối với từng nguyên tố có khả năng gây độc được tính theo công thức (1):

$$
\mathrm{ADD}=\frac{\mathrm{C} \times \mathrm{IR} \times \mathrm{EF} \times \mathrm{ED}}{\mathrm{BW} \times \mathrm{AT}}
$$

Trong đó $\mathrm{C}$ là nồng độ chất ô nhiễm trong nước $(\mathrm{mg} / \mathrm{L})$; IR thể tích nước sử dụng (L/ngày); EF hệ số phơi nhiễm/năm (ngày/năm); ED thời gian phơi nhiễm (365 ngày/năm x số tuổi (năm); $\mathrm{BW}$ trọng lượng cơ thể $(\mathrm{kg})$; AT thời gian trung bình (ngày).

Do ở nước ta chưa có các nghiên cứu chính thức về rủi ro và độc học môi trường nên các thông số xác định ADD (thể tích nước sử dụng và cân nặng) phù hợp với người Việt Nam vẫn chưa được công bố. Chính vì vậy, các nghiên cứu về rủi ro thường sử dụng thông số chuẩn của US EPA nên chưa thật sự phù hợp với điều kiện ở từng địa phương. Do đó, trong phạm vi đề tài, nhóm nghiên cứu đã tiến hành khảo sát thực tế các hộ gia đình sinh sống ở các khu vực lân cận giếng quan trắc để thu thập dữ liệu thực tế. Tổng cộng đã thu được 83 phiếu khảo sát, cụ thể như sau Quận 12 (31); Huyên Bình Chánh (10), Huyện Củ Chi (25) và Huyện Hóc Môn (7).

- Chỉ số rủi ro HQ (Hazard Quotient) xác định dựa trên ước tính $\mathrm{ADD}$ và giá trị độc tính (RfD) của từng nguyên tố theo công thức (2):

$$
\mathrm{HQ}=\frac{\mathrm{ADD}}{\mathrm{RfD}}
$$

HQ $\geq 1$ : Nguy cơ không chấp nhận được;

$\mathrm{HQ}<1$ : Nguy cơ chấp nhận được.

Trong cơ sở dữ liệu của US EPA không có giá trị RfD của Th nên ở khu vực nghiên cứu sẽ đánh giá được rủi ro trong trường hợp của $U$. RfD của $\mathrm{U}$ đã được xác định là $3 \times 10^{-3}$.

\section{Kết quả và thảo luận}

\subsection{Hàm lựng các nguyên tố phóng xạ}

Kết quả nghiên cứu đã cho thấy hàm lượng $\mathrm{U}$ và Th trong nước dưới đất ở cả ba tầng chứa nước đều tương đối thấp (Bảng 1). Nhìn chung, hàm lượng $U$ tăng cao ở tầng $\mathrm{qp}_{3}(154-2.020$ $\mathrm{ng} / \mathrm{L})$ so với các tầng $\mathrm{qp}_{2-3}(80-560 \mathrm{ng} / \mathrm{L})$ và $\mathrm{qp}_{1}$ (220-350 ng/1). Hàm lượng này khá thấp so với các nghiên cứu trước đây. Theo nghiên cứu của Babu và ctv, 2008 khi phân tích 52 mẫu nước giếng khoan ở huyện Kolar (Ấn độ) đã cho thấy hàm lượng $\mathrm{U}$ cao nhất lên đến $1.443 \times 10^{6} \mathrm{ng} / \mathrm{L}$ 


\section{BÀI BÁO KHOA HỌC}

[1]. Ở khu vực mỏ đất hiếm Đông Pao (Tỉnh Lai Châu) hàm lượng trung bình $U$ trong nước dưới đất là $476 \times 10^{3} \mathrm{ng} / \mathrm{L}[10]$. Do đó, có thể nhận xét rằng do sự khác biệt về thành phần thạch học của tầng chứa nước nên hàm lượng $\mathrm{U}$ ở khu vực nghiên cứu còn tương đối thấp, thể hiện hàm lượng nền. Và kết quả này cũng khẳng định trong các trầm tích sông và sông biển của khu vực TP.HCM không phổ biến các khoáng vật liên quan đến U. Tuy nhiên, đã có một số vị trí xuất hiện dị thường $U$. Hàm lượng cao của $U$ (trên $2.000 \mathrm{ng} / \mathrm{L}$ ) đã được xác định ở hai giếng Q011020 (khu vực Tân Chánh Hiệp), giếng Q013 (khu vực An Nhơn Tây, Củ Chi) thuộc tầng $\mathrm{qp}_{3}$. Hai giếng này đều nằm trong các $\mathrm{khu}$ vực sản xuất nông nghiệp (trồng hoa màu, chăn nuôi). Theo các kết quả đã công bố thì một số loại phân bón có chứa một lượng U nhất định [3]. Chính vì vậy, cần có các nghiên cứu chi tiết hơn về sự liên hệ giữa hoạt động nông nghiệp và dị thường $U$ tại hai vị trí nói trên.

Hàm lượng $U$ trong nước dưới đất không thể hiện tương quan rõ rệt với giá trị pH do số lượng mẫu khảo sát còn hạn chế. Nhưng ở các giếng có hàm lượng U cao (Q013, Q11020) thường thể hiện môi trường axit $(\mathrm{pH}<5)$ (Hình 2). Xu thế này phản ánh môi trường axit là môi trường thuận lợi để nguyên tố $U$ hòa tan và di chuyển trong môi trường nước [5].

Bảng 1. Sụ hiện diện của các nguyên tố phóng xạ (U và Th) trong nước dưới đất khu vực ngoại thành TP. HCM

\begin{tabular}{cccc}
\hline Nguyên tố & Tầng chứa nước & $\begin{array}{c}\text { Tần suất phát hiện } \\
(*)\end{array}$ & $\begin{array}{c}\text { Khoảng biến thiên } \\
(\mathrm{ng} / \mathrm{L})\end{array}$ \\
\hline \multirow{2}{*}{$\mathrm{U}$} & $\mathrm{qp}_{3}$ & $4 / 4$ & $154-2.020$ \\
& $\mathrm{qp}_{2-3}$ & $5 / 5$ & $\mathrm{KPH}-560$ \\
& $\mathrm{qp}_{1}$ & $2 / 2$ & $220-510$ \\
$\mathrm{Th}$ & $\mathrm{qp}_{3}$ & $2 / 4$ & KPH-1 \\
& $\mathrm{qp}_{2-3}$ & $1 / 5$ & KPH-50 \\
& $\mathrm{qp}_{1}$ & $1 / 2$ & KPH-3 \\
\hline
\end{tabular}

Ghi chú: Tần suất phát hiện: số mẫu có hàm lương > giới hạn phát hiện trên tồng số mẫu; KPH: Không phát hiện

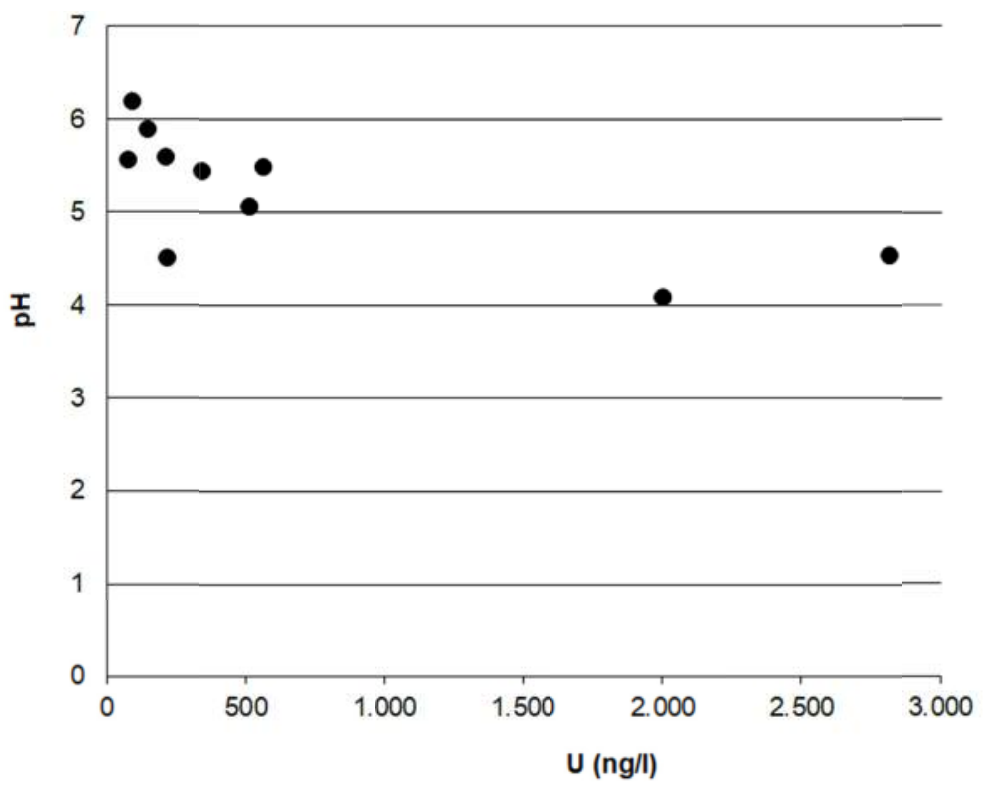

Hình 2. Tưong quan của $U$ và $p H$ ở khu vục nghiên cưu 
Hàm lượng Th thể hiện một xu thế khác biệt so với U. Theo chiều sâu, hàm lượng Th cao nhất là trong tầng Pleistocen giữa trên cao hơn giá trị ở tầng Pleistocen trên và tầng Pleistocen dưới (Bảng 1). Hàm lượng cao nhất $(50 \mathrm{ng} / \mathrm{L})$ tại giếng Q00202B thuộc xã Bình Mỹ huyện Củ Chi. So với $\mathrm{U}$, Th có hàm lượng thấp hơn nhiều. Sự gia tăng hàm lượng theo chiều sâu có thể phản ánh nguồn gốc tự nhiên do sự hoà tan của khoáng vật của nguyên tố này.

\section{3. Đánh giá rủi ro}

Qua khảo sát, phỏng vấn người dân địa phương trên địa bàn ngoại thành TP.HCM (huyện Hóc Môn, Bình Chánh, Củ Chi và quận 12), nước giếng sử dụng có độ sâu dao động trong khoảng 20 - 60m là độ sâu của tầng Pleistocen. Mục đích chính sử dụng nước của người dân là sinh hoạt (61\%). Ngoài ra, một tỷ lệ khá lớn các hộ dân cũng sử dung nguồn nước này phục vụ cho ăn uống (22\%). Bên cạnh đó, nước dưới đất cũng được sử dụng cho sản xuất và chăn nuôi $(17 \%)$. Theo tổ chức bảo vệ môi trường Hoa Kỳ (US EPA), rủi ro thường được xác định cho ba nhóm tuổi i) Trẻ em dưới 3 tuổi; ii) Người trưởng thành khoảng 30 tuổi; và iii) Người già trên 65 tuổi $[7,12]$. Tuy nhiên, qua thực tế khảo sát ở khu vực nghiên cứu, đã cho thấy nhóm tuổi trưởng thành chiếm đa số (45-61\%). Bên cạnh đó, có sự khác biệt về phân bố độ tuổi và lượng nước sử dụng (Bảng 2). Do đó dựa vào thực tế khảo sát ở khu vực nghiên cứu, cộng đồng địa phương được chia ra thành 5 nhóm đối tượng: < 3 tuổi; 3 - 24 tuổi; 25 - 35 tuổi; 36 - 65 và $>65$ tuổi. Các thông số khảo sát được trình bày tại Bảng 2.

Kết quả tính toán $\mathrm{ADD}$ và $\mathrm{HQ}$ được trình bày tại bảng 3 cho thấy giá trị HQ lớn nhất cho từng nhóm tuổi của $U$ đều thấp $(<1)$. Với nhóm tuổi nhỏ ( $<3$ tuổi) HQ là thấp nhất do lượng nước sử dụng ít và thời gian phơi nhiễm thấp. Giá trị HQ của 4 nhóm tuổi trưởng thành ( $>25$ tuổi) không có sự khác biệt rõ rệt. Do lượng nước sử dụng nhiều nên nhóm người trưởng thành ở độ tuổi 25 cao nhất. Mặc dù giá trị $\mathrm{HQ}<1$ thể hiện chưa có rủi ro đến sức khỏe nếu sử dụng nguồn nước này nhưng kết quả khảo sát thực tế đã cho thấy vẫn còn các hộ dân ở khu vực ngoại thành sử dụng nước dưới đất phục vụ cho mục đích ăn uống. Do đó, sự tăng cao hàm lượng $U$ ở một số vị trí vẫn cần được quan trắc thường xuyên và nghiên cứu chi tiết hơn.

Bảng 2. Kết quả khảo sát thực tế

\begin{tabular}{lccccc}
\hline \multirow{2}{*}{ Chỉ tiêu } & \multicolumn{5}{c}{ Nhóm tuổi } \\
\cline { 2 - 6 } & $<3$ tuổi & $3-24$ tuổi & $25-35$ tuổi & $36-65$ tuổi & $>65$ tuổi \\
\hline IR (1/ngày) & 0,3 & $0,5-2,1$ & $1,86-2,01$ & $1,98-1,74$ & 1,68 \\
BW (kg) & 13,5 & $15,5-68$ & $62-67$ & $66-58$ & 56 \\
AT (ngày) & 1.095 & $1.095-8.760$ & $9.125-12.775$ & $13.140-23.735$ & 23.725 \\
\hline
\end{tabular}

Bảng 3. Kết quả xác định HQ theo nhóm tuổi

\begin{tabular}{cccccc}
\hline Nguyên tố & $<3$ tuổi & $\geq 3$ đến 24 tuổi & $25-35$ tuổi & 36 đến 65 tuổi & $>65$ tuổi \\
\hline ED & 3 & $3-24$ & $25-35$ & $36-65$ & 65 \\
ADD & $2 \times 10^{-6}-63 \times 10^{-6}$ & $3 \times 10^{-6}-87 \times 10^{-6}$ & $2 \times 10^{-6}-84 \times 10^{-6}$ & $2 \times 10^{-6}-84 \times 10^{-6}$ & $2 \times 10^{-6}-84 \times 10^{-6}$ \\
HQ & $6 \times 10^{-4}-0,02$ & $8,4 \times 10^{-4}-0,03$ & $8,4 \times 10^{-4}-0,03$ & $8,1 \times 10^{-4}-0,03$ & $8,1 \times 10^{-4}-0,03$ \\
\hline
\end{tabular}

\section{Kết luận}

Kết quả phân tích cho thấy hàm lượng cả hai nguyên tố phóng xạ U và Th ở khu vực ngoại thành TP.HCM còn ở mức thấp thể hiện giá trị nền. Dựa trên các kết quả HQ cho thấy nguồn nước dưới đất ở khu vực nghiên cứu vẫn an toàn, mức rủi ro đến sức khỏe cộng đồng là rất thấp.
Tuy nhiên, ở một số khu vực đã có sự tăng cao hàm lượng $U$ trong tầng chứa nước Pleistocen trên có thể do hoạt động nhân sinh. Do đó, cần có các nghiên cứu chi tiết hơn và tần suất lớn hơn để có thể để đánh giá chính xác rủi ro đến sức khỏe cộng đồng. 


\section{BÀI BÁO KHOA HỌC}

Lời cảm ơn: Nhóm nghiên cưu trân trọng cảm ơn sụ hỗ trọ của Liên đoàn quy hoạch và điều tra tài nguyên nước miền Nam đã hỗ trợ nhóm nghiên cứu trong quá trình lấy mẫu.

\section{Tài liệu tham khảo}

1. Babu, M.N.S. (2008), Concentration of uranium levels in groundwater. International Journal of Environmental Science and Technology, 5 (2), 263- 266.

2. Đoàn Ngọc Toản (2016), Báo cáo tổng hợp kết quả điều tra, đánh giá tài nguyên nước dưới đất thành phố Hồ Chí Minh, Liên đoàn Quy hoạch và Điều tra tài nguyên nước miền Nam.

3. Khater, A.E. (2012), Uranium and trace elements in phosphate fertilizers in Saudi Arabia. Health Physics, 102 (1), 63-70.

4. Lauria, D.C., Almeida, R.M.R., Sracek, O. (2004), Behavior of radium, thorium and uranium in groundwater near the Buena Lagoon in the Coastal Zone of the State of Rio de Janeiro, Brazil. Environmental Geology, 47, 11-19. https://doi.org/10.1007/s00254-004-1121-1

5. Lê Khánh Phồn, Nguyễn Văn Nam (2020), Đặc điểm ô nhiễm phóng xa của nước biển lân cận các mỏ sa khoáng Titan. http://www.idm.gov.vn/Data/TapChi/2007/A300/a1.htm, truy cập ngày 20 tháng 2 năm 2020.

6. Murad, A., Alshamsi, D., Aldahan, A., Hou, X. (2014), Distribution of uranium and thorium in groundwater of arid climate region. Geophysical Research Abstracts, 16, EGU2014-13737. https://meetingorganizer.copernicus.orgEGU2014/EGU2014-13737.pdf, truy cập ngày 2 tháng 3 năm 2020.

7. Nguyễn Hào Quang (2014), Đánh giá rủi ro sưc khỏe đối với vấn đề ô nhiễm Asen (As) trong nước ngầm ở thành phố Hồ Chí Minh. Tạp chí Khoa học ĐHQGHN: Tạp chí Các khoa học về trái đất, 30 (1), 50-57.

8. Nguyễn Việt Kỳ, Trần Thị Phi Oanh, Hồ Chí Thông, Nguyễn Đình Tứ (2018), Diễn biến ô nhiếm kim loại trong nước duoói đất các tầng Pleistocene ở Thành phố Hồ Chí Minh trong giai đoạn 2000 - 2016. Science \& Technology Development Journal: Science of The Earth \& Environment, 2 (1), 24-32.

9. Phan, C.N., Ngô, D.C., Nguyễn, Đ.T., Bùi, T.V., Nguyễn, T.H., Phan, N.T. (2009), Tối ưu hóa mang quan trắc động thái nước duoói đất vùng thành phố Hồ Chí Minh. Báo cáo số 2010-04409/KQNC.

10. Vũ Thị Lan Anh (2014), Hiện trạng môi trường phóng xạ trong hoạt động thăm dò, khai thác quặng đất hiếm mỏ Đông Pao, huyện Tam Đuờng, tỉnh Lai Châu. http://www.hus.vnu.edu.vn/files/LuanVan/LuanVan-VuThiLanAnh-2014.pdf, truy cập ngày 20 tháng 2 năm 2020.

11. Waseem, A., Ullah, H., Rauf, M.K., Ahmad, I. (2015), Distribution of Natural Uranium in Surface and Groundwater Resources: A Review. Critical Reviews in Environmental Science and Technology, 45 (22), 2391-2423.

12. Wongsasuluk, P., Chotpantarat, S., Siriwong, W., Robson, M. (2014), Heavy metal contamination and human health risk assessment in drinking water from shallow groundwater wells in an agricultural area in Ubon Ratchathani province, Thailand. Environmental Geochemistry and Health, 36 (1), 169-82. 


\title{
RISK ASSEESMENT DUE TO THE PRESENCE OF RADIOUCLIDES (U AND Th) IIN GROUNDWATER OF SUBURB AREA, HOCHIMINH CITY
}

\author{
Hoang Thi Thanh Thuy ${ }^{1}$, Tu Thi Cam Loan ${ }^{1}$, Can Thu Van ${ }^{1}$, Van Tuan Vu${ }^{1}$ \\ ${ }^{1}$ Hochiminh City University of Natural Resources and Environment
}

\begin{abstract}
The present paper aimed to assess the health risk related to radionuclides ( $U$ and $T h$ ) levels in Pleistocene aquifers (Lower Pleistocene ( $\left.q p_{1}\right)$, Middle - Upper Pleistocene ( $q p_{2-3}$ ) and Upper Pleistocene ( $\left.\left.q p_{3}\right)\right)$. The water samples are collected from different suburban districts of Hochiminh City. The analysis of mentioned elements indicated a lower baseline values, in compare to (regions in) other countries. The health quota $(H Q)$ results did not exceed the limit of 1 , and thus the current concentration of $U$ and Th in the groundwater does not pose any threat to communities. Nonetheless, a few local anomalies have been observed, and therefore further study is required for a more precise conclusion.
\end{abstract}

Keywords: Groundwater, radionuclides, uranium, thorium, risk assessment, hazard quotient.

Phu lục 1: Vị trí các điểm quan trắc nuoớc dưới đất của Liên đoàn Điều tra và Quy hoạch tài nguyên nước miền Nam

\begin{tabular}{|c|c|c|c|c|}
\hline STT & $\begin{array}{l}\text { Tầng } \\
\text { chứa } \\
\text { nước }\end{array}$ & Số lượng giếng & Độ sâu (m) & Nguồn tác động \\
\hline 1 & $\mathrm{qp}_{3}$ & $\begin{array}{c}4 \\
\text { (Huyện Củ Chi: 3, Q. 12:1) }\end{array}$ & $15-37,5$ & $\begin{array}{l}\text { Khu dân cư, sản xuất nông nghiệp } \\
\text { (trồng hoa màu và chăn nuôi) và } \\
\text { khu công nghiệp (?) }\end{array}$ \\
\hline 2 & $\mathrm{qp}_{2-3}$ & $\begin{array}{c}5 \\
\text { (Huyện Bình Chánh, Huyện Hóc } \\
\text { Môn: 1; Huyện Củ Chi: 1; Quận } \\
\text { 12: 2) }\end{array}$ & $42-74$ & $\begin{array}{l}\text { Khu dân cư, Khu công nghiệp Vĩnh } \\
\text { lôc A(?), Tam Bình (?); sản xuât } \\
\text { nông nghiệp (trồng hoa màu }\end{array}$ \\
\hline 3 & $\mathrm{qp}_{1}$ & $\begin{array}{c}2 \\
\text { (Huyện Củ Chi: 1; Quận 12: 1) }\end{array}$ & $66-93$ & $\begin{array}{l}\text { Khu dân cư, Khu công nghiệp (Nhà } \\
\text { máy bia Heineken A?) }\end{array}$ \\
\hline
\end{tabular}

